\title{
Sclerotic Bone Metastases Diagnosed on DEXA
}

$\checkmark$ Pickard ${ }^{1}, T L$ Goh $^{1}$, CJL Kueh$^{2}$, A Gallagher ${ }^{2}$

${ }^{1}$ Undergraduate Medical School, University of Glasgow, Glasgow G12 8QQ

${ }^{2}$ Queen Elizabeth University Hospital, Glasgow G51 4TF

Identifier/Topic: Clinical Bone and calcium

Greater Glasgow and Clyde

\section{Case History}

A 79 year old gentleman sustained a traumatic fracture of his left humerus in November 2016. Given his age and non-union fracture condition, he was referred for a DEXA scan in May 2017 and multiple sclerotic bone lesions in hip and spine were revealed. T-score was artificially high, with a score of 6.6 at L2-L4. Subsequent review of his plain $x$-rays revealed sclerotic lesions in the ribs, left clavicle and humerus.

The patient has a past medical history of type 2 diabetes mellitus, hypertension, asthma and kidney stones. He was started on finasteride in 2011, presumably for treatment of prostatic symptoms. His bone profile taken in October 2016 revealed elevated alkaline phosphatase (1464U/L).

\section{Investigations and Methods}

The multiple sclerotic lesions shown on x-ray were highly suggestive of bony metastasis. The primary malignancy that causes metastatic sclerotic bone lesions in a male is prostate cancer $^{1}$. Given the findings of the DEXA scan, initial plan was to do a PSA test to confirm or refute primary prostate cancer; $\mathrm{CT}$ chest/pelvis/abdomen; and nuclear bone scan?2.

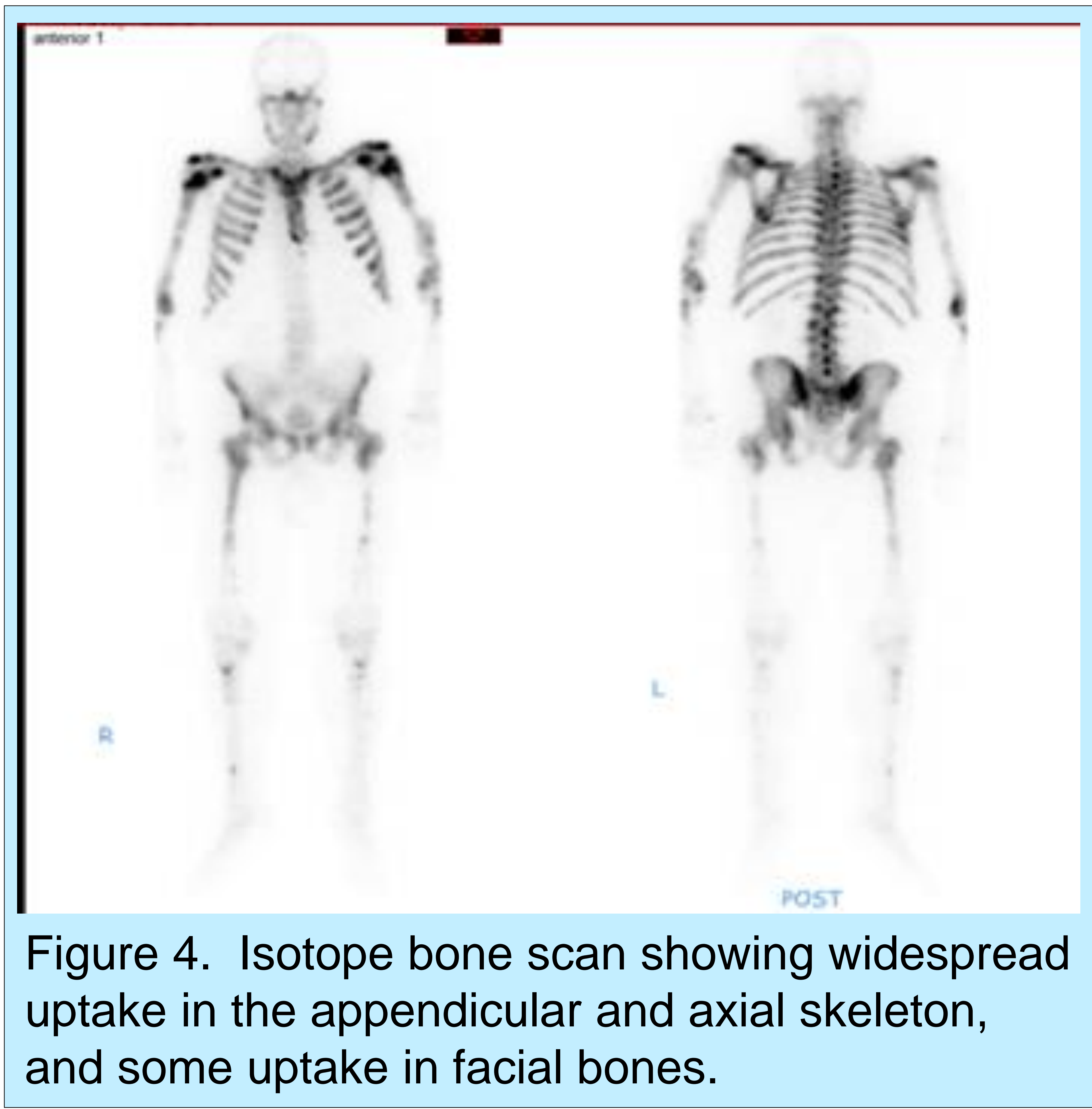

\section{Results and Treatment}

PSA came back at 1478.5 and alkaline phosphatase was also significantly raised. His isotope bone scan revealed significant uptake in his axial, appendicular skeleton and facial bones.

\section{Conclusion and Points for Discussion}

The results are in line with a diagnosis of metastatic prostate cancer. An interesting point about this case was the route of diagnosis. Unfortunately, the sclerotic bone lesions identified on this patient's admission $x$ rays in November 2016 were overlooked by the orthopaedic surgeons, and it was in fact interpretation of the DEXA scan that identified the bony metastases. Ideally, the lesions would have been identified along with the fracture of the humerus, and if this was the case the patient would have had the same line of investigations as above, but significantly earlier.

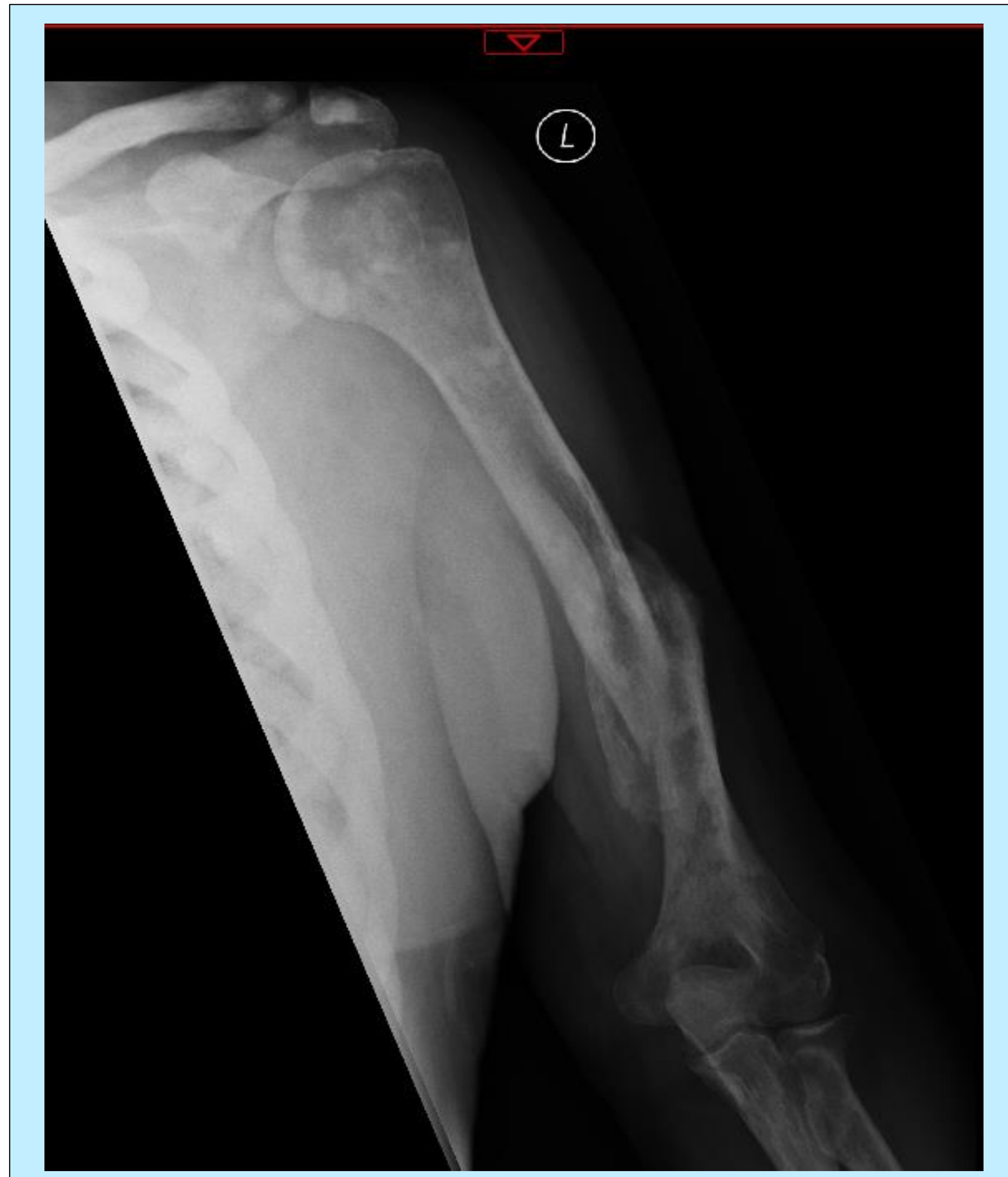

Figure 1. Humeral fracture with sclerotic lesions in ribs, clavicle and humerus

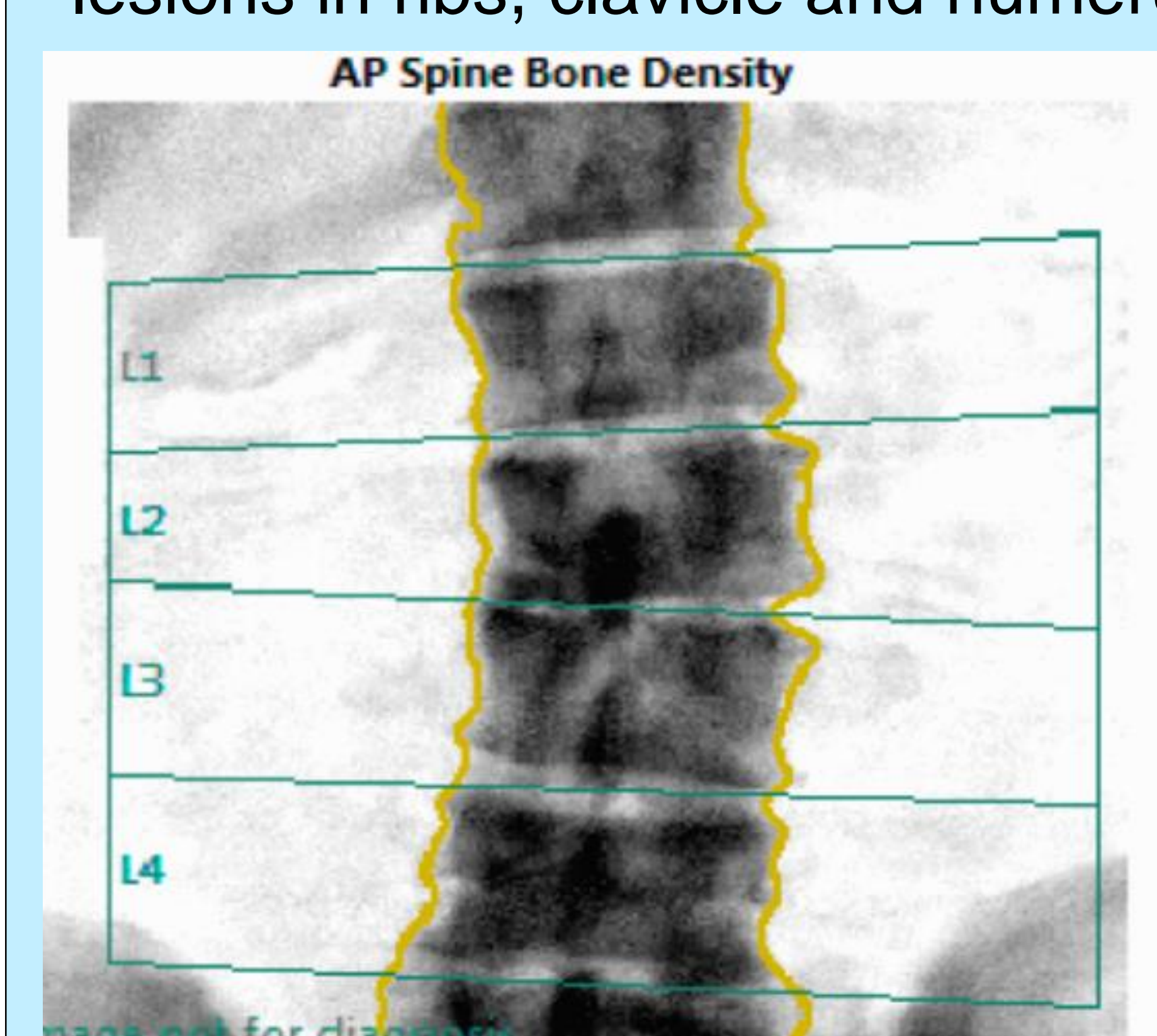

Figure 3. Dexa scan results showing sclerotic bone lesions in spine and raised T-score at L2-4.

\section{References}

1. Suva LJ, Washam C, Nicholas RW, Griffin RJ. Bone metastasis: mechanisms and therapeutic opportunities. Nat Rev Endocrinol 2011; 7(4): 208-218. https://www.ncbi.nlm.nih.gov/pmc/articles/PMC3134309/ (accessed 17 June 2017).

2. Heindel W, Gubitz R, Vieth V, Weckesser M, Schober O, Schafers M. The diagnostic imaging of bone metastases. Dtsch Arztebl Int. 2014; 111(44): 741-747. https://www.ncbi.nlm.nih.gov/pmc/articles/PMC4239579/ (accessed 17 June 2017).

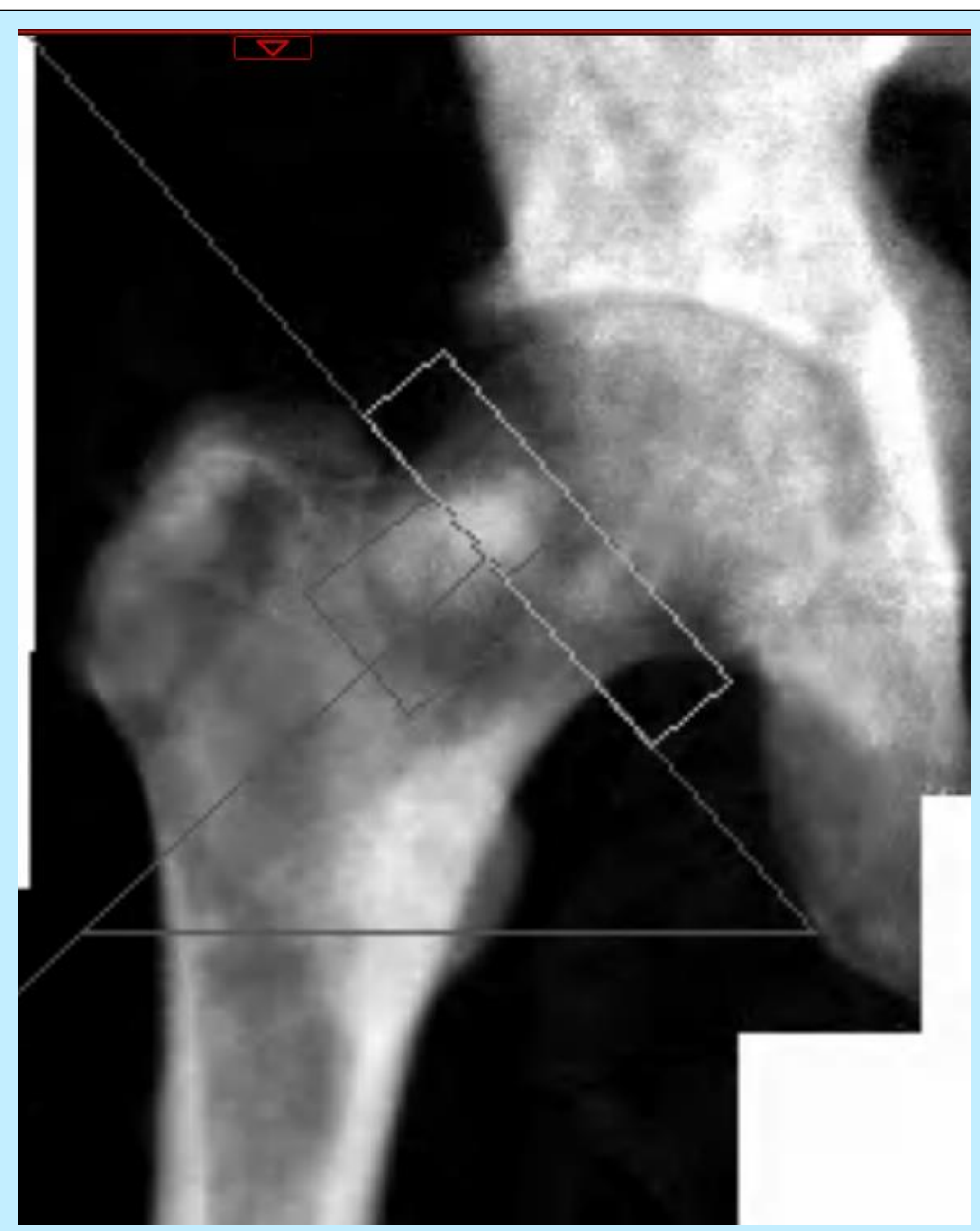

Figure 2. DXA scan of right hip showing sclerotic lesions

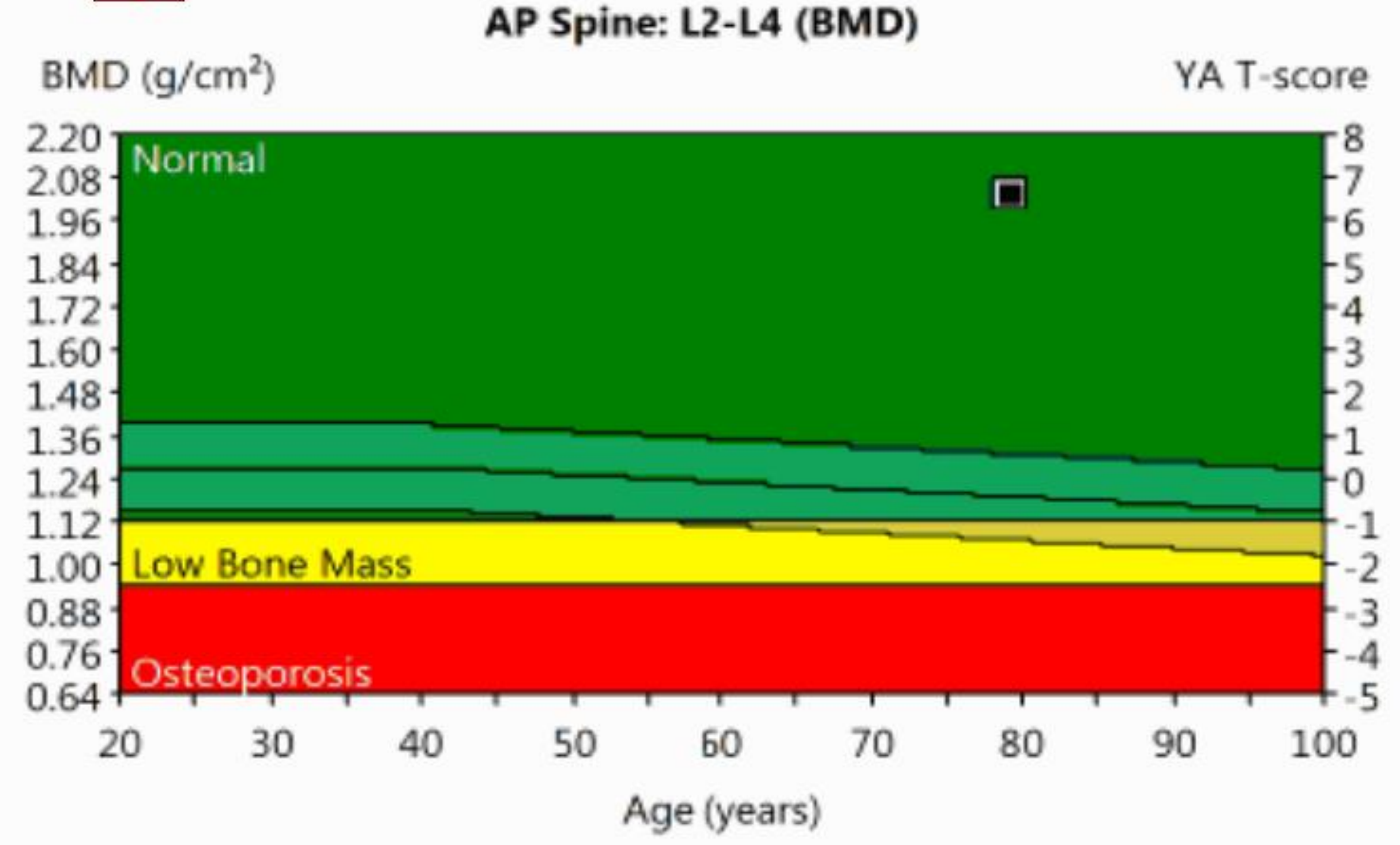

T-score

\section{re}

